\title{
The National Resuscitation Council, Singapore, and 34 years of resuscitation training: 1983 to 2017
}

\author{
Venkataraman Anantharaman ${ }^{1,2,3,4}$, MBBS, FRCSEd
}

\begin{abstract}
Training in the modern form of cardiopulmonary resuscitation (CPR) started in Singapore in 1983. For the first 15 years, the expansion of training programmes was mainly owing to the interest of a few individuals. Public training in the skill was minimal. In an area of medical care where the greatest opportunity for benefit lies in employing core resuscitation skills in the prehospital environment, very little was being done to address such a need. In 1998, a group of physicians, working together with the Ministry of Health, set up the National Resuscitation Council (NRC). Over the years, the NRC has created national guidelines on resuscitation and reviewed them at five-yearly intervals. Provider training manuals are now available for most programmes. The NRC has set up an active accreditation system for monitoring and maintaining standards of life support training. This has led to a large increase in the number of training centres, as well as recognition and adoption of the council's guidelines in the country. The NRC has also actively promoted the use of bystander CPR through communitybased programmes, resulting in a rise in the number of certified providers. Improving the chain of survival, through active community-based training programmes, will likely lead to more lives being saved from sudden cardiac arrest.
\end{abstract}

Keywords: accreditation, cardiopulmonary resuscitation, community-based training, defibrillation, life support instructors

\section{INTRODUCTION}

The first structured course in cardiopulmonary resuscitation (CPR) in Singapore was conducted in 1983 at Singapore General Hospital (SGH). It was organised by a group of doctors who were concerned about the lack of formal training in this skill in the country. ${ }^{(1)}$ They followed closely the guidelines that had been drawn up and used by the American Heart Association for implementation in the United States. Since then, other life support courses have been organised in various public and private healthcare institutions, as well as in many private life support training centres that have sprung up over the last 33 years. The objective of this paper is to take stock of the development of resuscitation and life support training over the years so as to better plan for the future.

Age-standardised mortality rates for coronary heart disease in Singapore have changed over the years, from 27.0 per 100,000 population in 1957 to 71.0 per 100,000 population in $1984,{ }^{(2)}$ before gradually decreasing to $67.0,44.3$ and 30.7 per 100,000 population in 1987, 2007 and 2012, respectively. ${ }^{(3)}$ Over this time period, the rate of cardiac arrest, whether out-of-hospital or in-hospital, was initially not clearly documented. Generally, it was believed that the survival rate for out-of-hospital cardiac arrests (OHCAs) was less than $1 \%$. The first record of OHCA in Singapore, created between 2001 and 2002, documented about 940 out-of-hospital deaths over a one-year period. ${ }^{(4)}$

\section{CARDIOPULMONARY RESUSCITATION TRAINING}

The first formal training programmes in modern methods of CPR were conducted at Ward 52A of SGH. The objectives of thethen eight-hour training were to: (a) build a dedicated faculty of instructors; (b) train all current SGH house officers in CPR; (c) set standards for CPR training and testing; and (d) better understand the attitudes of staff toward CPR training.

The initial course, Basic Cardiac Life Support (BCLS), was an eight-hour session with six modules, viz. adult one-person CPR, adult two-person $\mathrm{CPR}$, conscious adult with foreign-body airway obstruction (FBAO), unconscious adult with FBAO, infant CPR and infant FBAO. Theory and practical tests were conducted in these six modules. Soon after, instructor courses were started in order to grow a sizeable instructor pool to address training needs.

After two years of conducting the programme in a hospitalbased environment and training mainly healthcare workers, a small group of trained instructors introduced public participation into the process by setting up the first public-oriented CPR training programme at the Singapore Red Cross Society in 1985. Training of the public began enthusiastically, with fortnightly courses initially conducted for Red Cross members and subsequently for other members of the public keen on learning basic resuscitation skills. Instructor courses were also started at the Red Cross Society to increase the pool of instructors for public training. To add quality and structure to public training, the Red Cross Society adopted a code of standards in their CPR training programmes.

Over the years, all public and private hospitals have embraced these programmes. A five-year review of the BCLS courses conducted between 1985 and 1990 at SGH ${ }^{(5)}$ documented a total number of 1,789 trained providers, of whom $33.3 \%$ were doctors, $63.5 \%$ nurses, and the remaining 3.2\% comprised radiographers, laboratory technicians, physiotherapists, dental surgeons and firstaiders. Of these, only $65(3.6 \%)$ were eventually trained to be instructors, even though $23.2 \%$ of all trained providers expressed a willingness to teach the skills.

${ }^{1}$ National Resuscitation Council, ${ }^{2}$ Department of Emergency Medicine, Singapore General Hospital, ${ }^{3}$ National University of Singapore, ${ }^{4}$ Duke-NUS Medical School, Singapore Correspondence: Prof Venkataraman Anantharaman, Chairman, National Resuscitation Council and Senior Consultant, Department of Emergency Medicine, Singapore General Hospital, Outram Road, Singapore 169608. anantharaman@singhealth.com.sg 


\section{ADVANCED CARDIAC LIFE SUPPORT TRAINING}

The first Advanced Cardiac Life Support (ACLS) course was started in late 1985 by a group of five doctors and one senior nurse, who also served as instructors. They had acquired the necessary knowledge and skills through self-teaching and begun conducting the programme at $\mathrm{SGH}$. The manuals used were borrowed from the American Heart Association, and the drug names and dosages were customised to conform to what was available in Singapore. In the first five years of the programme, ${ }^{(5)}$ only 222 doctors and 45 nurses were trained, and there were only 14 ACLS instructors.

After 1990, active steps were undertaken to get all doctors posted to hospital emergency departments to be ACLS-certified. This naturally led to more doctors being trained, although there was only a single centre conducting the training. It was only in the later part of the 1990s that other hospitals began setting up ACLS training programmes that were similar to the ones being conducted at $\mathrm{SGH}$. This helped to address the need to train the increasing number of doctors who were seeking certification in these skills. The private sector, however, had already started such training programmes in the early 1990s, at Mount Elizabeth Medical Centre.

\section{DEFIBRILLATION TRAINING}

Formal training in cardiac defibrillation as part of a life support programme was started in early 1989 for the purpose of introducing automated external defibrillators (AEDs) to the Emergency Ambulance Services. A 12-hour training programme, designed for 24 ambulance officers, was conducted at SGH over four days in April 1989. ${ }^{(5)}$ At the same time, the first two AEDs to be deployed in Singapore - each costing about SGD 15,000 then - were purchased with funds donated by the then-Singapore National Heart Association (forerunner of the current Singapore Heart Foundation) and gifted to the Singapore Civil Defence Force for use in their emergency ambulances. Within two weeks of completion of training, the first case of cardiac arrest survival from the use of an AED in Singapore was encountered - a 37-year-old electrician who had gone into ventricular fibrillation following an electrical injury was successfully defibrillated by a trained ambulance officer. These two defibrillators remained in use by the Emergency Ambulance Services till 1995 when all emergency ambulances were equipped with AEDs and all ambulance staff were trained in their use.

Other than in the Emergency Ambulance Services, AED use remained extremely low in Singapore until the first decade of the 21st century. Singapore Airlines was one of the first major organisations that adopted the use of AEDs in all its aircrafts, as well as training all its cabin crew chiefs and organising refresher programmes on the use of AEDs.

In order to simplify the process of training and thereby increase the number of trained members of the public, the National Resuscitation Council (NRC) combined the essential elements of the CPR programme with the defibrillation programme into a single, integrated, three-hour CPR+AED programme in January 2005. This step was taken because the skills of both CPR and defibrillation must be brought to bear on collapsed patients in an integrated fashion. Furthermore, separate teaching of the skills had led members of the public to believe that either one of the skills was adequate for successful resuscitation. Over the last 12 years, this integrated programme has become the most popular and wellattended of the life support training programmes in the country.

\section{PAEDIATRIC LIFE SUPPORT TRAINING}

Paediatric life support training began in the mid-1990s with the start of two programmes: Basic Resuscitation Course (BRC) for children and Advanced Resuscitation Course (ARC) for children. The courses were initially run by the Singapore Paediatric Society (SPS), but were also adopted by the KK Women's and Children's Hospital (KKH) a few years later. The ARC, subsequently renamed the Advanced Paediatric Life Support (APLS) Programme, was led by the SPS, while KKH continued conducting the BRC and also introduced a Child First Aid programme in collaboration with the Singapore Red Cross Society. The APLS programme continues to be managed by both SPS and $\mathrm{KKH}$.

In 2013, the Neonatal Resuscitation Course was introduced at SGH. This course has gained acceptance by the paediatrics community as one of the standard life support courses for the younger age group. Persons who attend the APLS programme are usually from the disciplines of Paediatrics and Emergency Medicine. Those attending the BRC and Child First Aid programme are usually childcare teachers and young parents. Over the last few months, a prehospital paediatric life support programme has also been introduced for prehospital emergency care workers.

\section{NATIONAL RESUSCITATION COUNCIL}

With the low usage of AEDs, the large number of life support programmes springing up in the country and the realisation that these programmes needed to be streamlined, the Ministry of Health $(\mathrm{MOH})$ set up the NRC in 1998 with the following goals: (a) to support the teaching and practice of resuscitation; (b) to act as a coordinating body representing major groups involved in the teaching and practice of resuscitation; (c) to promote uniformity and standardisation in resuscitation practices; and (d) to provide direction, national policies and guidelines for the teaching and practice of resuscitation. The specific roles identified for the NRC by the $\mathrm{MOH}$ are outlined in Box 1. The list of organisations that currently constitute the NRC is shown in Box 2, while the types of programmes that are currently accredited by the NRC are shown in Box 3.

\section{NATIONAL RESUSCITATION GUIDELINES}

One of the early tasks that the council set out to accomplish was the creation of national resuscitation guidelines. The first of these guidelines was published in 2001, ${ }^{(6-8)}$ soon after the release of the first International CPR Guidelines by the International Liaison Committee on Resuscitation (ILCOR) in August 2000. The ILCOR document was distributed to members of the NRC subcommittees on basic life support, defibrillation, ACLS and paediatric life support. After a series of meetings, the first set of national resuscitation guidelines was produced and published. The release of the 2005 ILCOR International Consensus on Cardiopulmonary Resuscitation and Emergency Cardiovascular Care Science with 

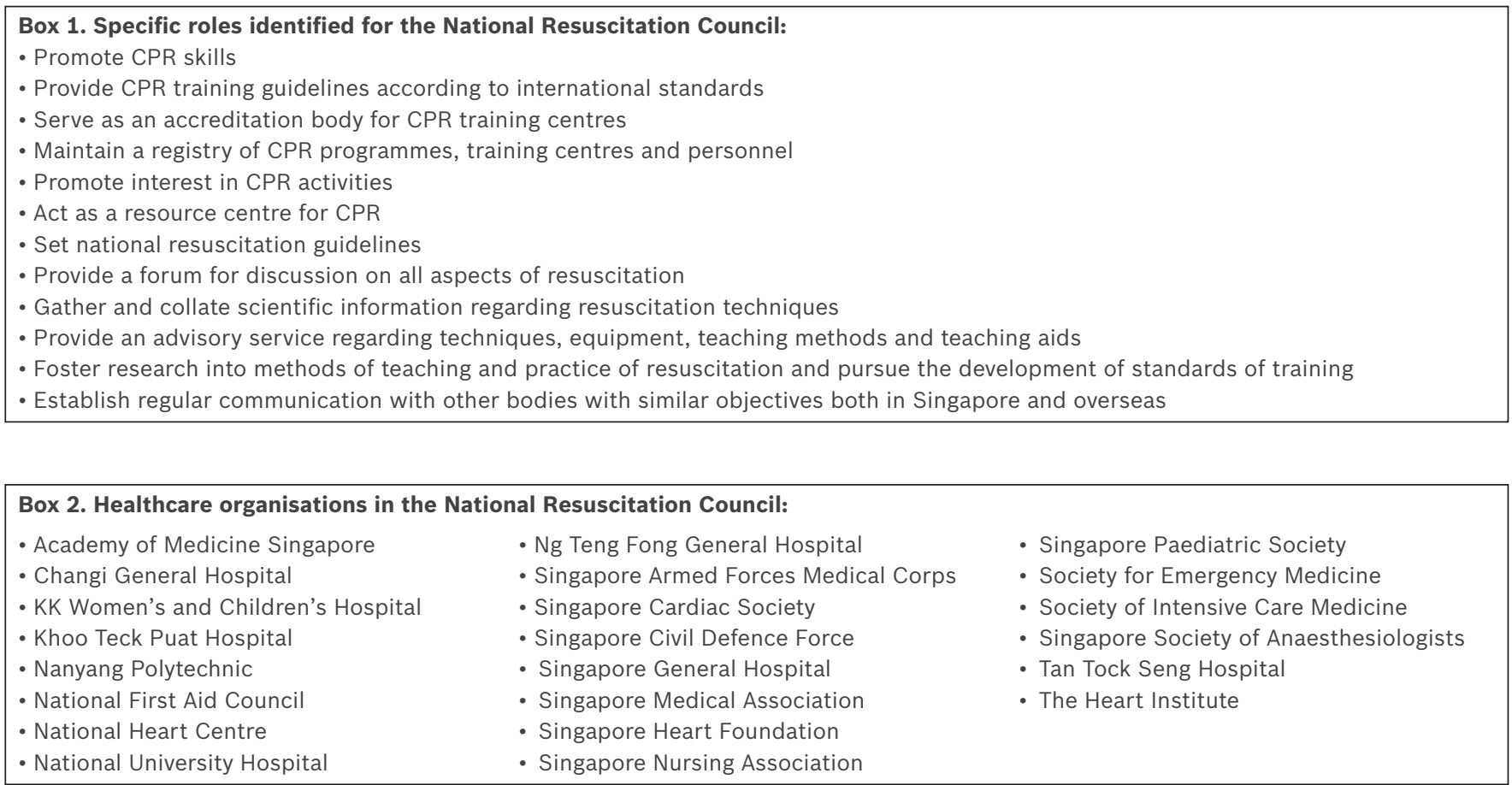

Box 3. Programmes currently accredited by the National

Resuscitation Council:

- Basic Cardiac Life Support (BCLS) Course

- CPR+Automated External Defibrillation (AED) Course

- BCLS+AED Course

- Advance Cardiac Life Support (ACLS) Course

- Advanced Paediatric Life Support (APLS) Course

- Neonatal Life Support Course

- Paediatric Prehospital Life Support Course

- Life Support Course for Nurses

- BCLS Instructors' Course

- CPR+AED Instructors' Course

- ACLS Instructors' Course

- Life Support Course for Nurses Instructor Course

Treatment Recommendations (CoSTR) was followed by the release of the 2006 Singapore Resuscitation Guidelines. ${ }^{(9)}$ The first full set of national resuscitation guidelines ${ }^{(10-13)}$ for the country was published in 2011, after the release of the ILCOR 2010 CoSTR documents. In addition to national resuscitation guidelines, the NRC has also released guidelines and position statements on special areas of concern, especially on compression-only $\mathrm{CPR}^{(14)}$ and CPR+AED facility management programmes. ${ }^{(15)}$

The release of national guidelines was important, as it indicated that Singapore could not adopt wholesale what other countries had created for themselves, but needed to go through available scientific evidence, understand the relevance of such literature to local cardiac arrest situations and then decide what was most appropriate for best practice locally. The process also helped the creators of resuscitation guidelines to become more familiar with resuscitation research and methodology, and to be cognisant of the need to carefully scrutinise the manner in which the research was conducted before accepting, rejecting or addressing the relevance of the available evidence to local situations.
Since 2011, the NRC has also created national provider training manuals on most of the programmes covered by the council. These manuals have helped standardise understanding and interpretation of resuscitation guidelines in the local context. Currently, existing provider training manuals produced by the NRC include the following: BCLS Provider Manual; CPR+AED Provider Manual; ACLS Provider Manual; CPR+AED Instructor Training Manual; and NRC Instructors Handbook.

In addition to releasing guidelines and creating training manuals, the council has been involved in a variety of activities over the years to move forward the cause of good resuscitation in Singapore. These are described in the following paragraphs.

\section{ACCREDITATION OF LIFE SUPPORT TRAINING CENTRES}

In the early years of the NRC, we recognised the need to establish clear training standards in the various life support programmes. Therefore, standardised curricula, minimum standards of coverage of various topics and practical training standards were adopted. Examples of standards adopted included setting an instructor-to-trainee ratio of not more than six trainees per instructor in life support programmes, ensuring consistency of teaching content with national guidelines, and maintaining the quality of instruction and assessment during training sessions. Standardised check lists were also produced for each type of programme conducted under the umbrella of the council.

Separate teams of training auditors (senior instructors who had distinguished themselves as teachers who possessed excellent skills and integrity) were set up to conduct audits of the training centres and programmes. Successful audit resulted in the NRC's accreditation of the centre to conduct a particular programme. The duration of accreditation was initially set at three years. However, after the release of the 2006 national guidelines, it 
was opined that attrition in knowledge and skills after three years of initial training was very significant. Consequently, the duration of accreditation was amended to two years, and it has remained so. Training centres that have undergone successful audits are permitted to state that their programme is accredited by the NRC, as well as use the NRC logo on their certificates. The formal nature of the accreditation process, coupled with the methodological and structured approach adopted by the audit teams and the diligence with which they approached their tasks, has led to NRC accreditation being accepted as the trademark for good training standards by all organisations that require their staff to be certified in these skills.

\section{PROMOTING RESUSCITATION TRAINING WITHIN THE COMMUNITY}

At the time of formation of the NRC, there were about ten centres in Singapore conducting various forms of cardiac life support training: four were based in public hospitals; one was in a large private healthcare group; a few were with large first aid training organisations, such as the Singapore Red Cross Society, St John Ambulance Singapore, Singapore Armed Forces Medical Training Institute and Singapore Life Saving Society; and one was based in a residential community.

The standardisation of training programmes, the development of a system of training accreditation and the gradual increase in number of trained instructors have led to the establishment of life support training centres in the heartland, where the public live and work. The first of these was Life Saving Training Centre, set up in Yishun township in 1995. ${ }^{(16)}$ Following the establishment of the NRC, the number of training centres started to increase. In 2007, there were 24 NRC-accredited life support training centres in the country. By January 2017, the number of accredited training centres for the various life support programmes has grown considerably (see Table I).

With the increased availability of training centres, more people have also been trained in these key life support skills annually. Although the reported figures may not be accurate owing to a lack of confirmed feedback from some training centres, the estimated number of persons trained in accredited CPR+AED programmes in 2008 was 32,000, and increased to 84,000 in 2015 . Some reasons for the rise in number of trained providers include a greater awareness among the public of the need for CPR+AED training; annual campaigns, such as National Life Saving Day, organised by the NRC to promote awareness of resuscitation; and an increasing need by service organisations to have staff trained and certified in these skills to maintain their state of readiness.

\section{Commercial organisations}

Soon after the launch of the CPR+AED provider training programme in early 2005, the NRC began approaching community organisations to adopt such training for their staff. The first major collaboration was with large hotels in Singapore. By the end of 2006, almost all major hotels in the country had adopted the CPR+AED programme, deployed AEDs in their
Table I. Number of programme-specific National Resuscitation Council-accredited training centres in Singapore as of January 2017.

\begin{tabular}{lc}
\hline Programme & No. \\
\hline BCLS Course & 75 \\
CPR+AED Course & 106 \\
BCLS+AED Course & 8 \\
ACLS Course & 7 \\
Advanced Paediatric Life Support Course & 1 \\
Neonatal Life Support Course & 2 \\
Prehospital Paediatric Life Support Course & 1 \\
Life Support Course for Nurses & 11 \\
BCLS Instructors' Course & 17 \\
CPR+AED Instructors' Course & 19 \\
ACLS Instructors' Course & 2 \\
Life Support Course for Nurses Instructor Course & 3 \\
\hline
\end{tabular}

ACLS: advanced cardiac life support; AED: automated external defibrillator; BCLS: basic cardiac life support; CPR: cardiopulmonary resuscitation

premises and sent at least some of their security staff for training in such life-saving skills. Other establishments, such as convention facilities and shopping malls, also began adopting the programme at about that time. In January 2008, through a collaboration with the National Fire and Civil Emergency Preparedness Council, the NRC brought together 107 commercial organisations in the country to launch the CPR+AED programme in commercial and industrial areas.

\section{Schools}

Pilot programmes were initiated in a few secondary schools and junior colleges to teach these basic core skills to, and certify, schoolteachers and students of Secondary 3 level and above. However, the burden of curriculum time and the additional workload for schoolteachers who were being trained as instructors became apparent. These difficulties were surfaced to the $\mathrm{MOH}$ and, in response, the ministry requested the assistance of the NRC to come up with a fresh approach for schools. The First Responder Training System for Schools was designed by the NRC and submitted to the MOH in January 2012. The proposed programme emphasised the need to offer training programmes of different levels of complexity to students of different age groups. While common themes were to be stressed at every level of training, relatively complex skills would be taught in stages and at a later stage in the training cycle. ${ }^{(17)}$ It would likely dedicate more time to teaching specific basic areas to the younger age groups, so as to build the foundations for the teaching and practice of the more complex skills at the later stages. The programme also made provision for repetition of a variety of psychomotor skills at two-yearly intervals for the purpose of skills retention and sustained behavioural change. The intention was to demonstrate improvement in bystander responder rates for casualties of sudden cardiac arrest. To ensure better skills retention, the programme had scope for refresher training of a short duration for those who had previously been trained. Through the recently set up Unit for Prehospital Emergency Care, $\mathrm{MOH}$ has begun $\mathrm{CPR}+\mathrm{AED}$ awareness programmes in schools and will consider giving 
Box 4. Major milestones of National Life Saving Day from 2011 to 2017:

- January 2011: The programme trained and certified a total of 7,909 persons in CPR in a single day at a single venue, achieving entry into the Guinness Book of World Records.

- January 2012: More than 2,877 public citizens were trained and certified in the combined skills of CPR+AED in a single day at a single venue, achieving entry into the Guinness Book of World Records.

- January 2013: A total of 3,328 members of the public gathered for 'Walk to Save a Life' at the War Memorial Park on Beach Road under the auspices of the NRC. Participants walked around the city centre, stopping at ten life-saving stations, each depicting one aspect of life saving: preventing heart attacks; early access; early CPR; early defibrillation; early advanced life support; injury prevention; CPR+AED training; community first aid; sports first aid; and traffic safety.

- January 2014: National Life Saving Day moved for the first time to the heartlands. A large mass CPR+AED event was held at Woodlands with active collaboration of PA. About 4,000 local residents were trained in these skills. Following this event, PA independently established CPR+AED training programmes to train their community emergency response teams and interested residents living in various wards in this life saving skill.

- January 2016: The NRC launched the Citizen First Responder programme in close collaboration with the National First Aid Council (NFAC). This was conducted at the Pasir Ris area and consisted of a two-hour CPR+AED training programme and a three-hour citizen first aid training programme. About 3,600 persons participated in this event. Following this event, the Singapore Red Cross Society adopted the programme and organised instructor and provider courses in Citizen First Response.

- January 2017: The NRC organised a public forum on the theme 'Saving Our Hearts, Saving Our Lives'. Three talks were conducted covering these topics: magnitude of the problem; why people die from sudden cardiac arrest; and what can be done to minimise deaths and improve survival. About 400 people participated in this event.

support to graduated skills training programmes in schools and the community.

\section{The local community}

Nearly $70 \%$ of all OHCAs in Singapore occur in residential communities. ${ }^{(4)}$ However, the rate of bystander CPR in such environments has remained extremely low. In addition, prior to 2008, there were no AEDs located in residential communities in Singapore. In 2008, two community-based programmes ${ }^{(18)}$ were started in two residential communities: Bukit Merah View and Jalan Kayu.

The programme in the Bukit Merah View neighbourhood in the Henderson constituency was conducted in collaboration with the community grassroots organisations of that constituency, and was the first such programme in Singapore and, possibly, in any part of the world. It involved the deployment of an AED at the ground-floor lift lobby of every high-rise apartment block and at the grocery market (a total of 21 AEDs were installed). A programme to train residents of the neighbourhood and constituency in the skills of CPR+AED was also started. The Henderson Heartbeat programme trained more than 500 residents within the first two years, and helped to increase awareness of the need for self-help and community preparedness.

The second programme introduced in the Jalan Kayu constituency, known as the FACTs (First Aid and Cardiac Training system) project, focused on the skills of CPR and essential basic first aid. Courses were conducted over a five-hour period by a group comprising mainly volunteer medical students from the National University of Singapore. The medical students had received instructor training, with a focus on practical skills and the use of handy flip charts, manikins and first aid equipment. The FACTs programme trained 400 people in its first year of operation.

The two programmes had received active support from the local community and positive feedback from the course participants. This shows that community residents are willing to come forward to prepare themselves for management of emergencies, if there are active reach-out programmes and courses that focus on practical skills and are presented in an easy-to-understand manner. These community-based programmes were a precursor to the first-responder programmes that were later introduced. In addition, the NRC provided assistance to other groups that wished to train community residents in $\mathrm{CPR}+\mathrm{AED}$, and helped set up AED programmes in other constituencies, such as in Toa Payoh East for the Adventist Home for the Elders.

\section{National Life Saving Day}

Over the past five years, the most high-profile programme has been the designation of the third Sunday of January since 2011 as National Life Saving Day. Initiated by the NRC in 2011, this programme has actively sought to raise community awareness of the need to exercise safety in daily work life, minimise the risks of cardiac arrest and injuries, and actively intervene in the event of an emergency with the use of CPR, AED and basic first aid skills. As a prerequisite, National Life Saving Day involves active collaboration with a variety of community organisations. Such collaborations not only helped to raise awareness of the need for $\mathrm{CPR}+\mathrm{AED}$ training in the country, but also brought on board two major organisations, viz. the Singapore Sports Council and People's Association. Both organisations have gone on to adopt these programmes and are now increasingly active in promoting $\mathrm{CPR}+\mathrm{AED}$ training in their areas of influence. National Life Saving Day has also been a catalyst for other accredited training centres to dive actively into the area of public $\mathrm{CPR}+\mathrm{AED}$ training. For instance, the Singapore Heart Foundation is now coordinating the national AED registry. Major milestones of National Life Saving Day from 2011 to 2017 are summarised in Box 4.

These National Life Saving Day events have actively contributed to helping more members of the community learn CPR and use their skills to save lives. It is noteworthy that bystander CPR rates started increasing from early 2011, in conjunction with the launch of National Life Saving Day. Ng et al reported in their article ${ }^{(19)}$ that by the end of 2015 , the local bystander CPR rate had reached $49 \%$, of which only $8 \%$ was 
owing to dispatcher-assisted CPR. The remainder of the increase, from $22 \%$ to $41 \%$ (almost doubling), was attributed to public, bystander-initiated CPR. The annual campaigns and community outreach efforts led by the NRC could have played an active role in the increase in bystander CPR rates.

\section{TRAINING INSTRUCTORS}

Our instructors form the backbone of life support training programmes in the community. The number of instructor training courses conducted is just enough to manage attrition and meet the need for additional instructors in existing instructor training centres, most of which are located in public healthcare institutions. In addition to conducting courses at these centres, instructors are also needed in the other training centres, especially those that train members of the public.

Over the last six years, the NRC has used the opportunities afforded by the mass training sessions organised at National Life Saving Day to train instructors to teach the community the basic skills of CPR and AED use. Over the years, close to 1,800 new instructors have been trained via this route. Senior instructors from the various accredited training centres have repeatedly volunteered to teach at these NRC-organised instructor training sessions. They have no doubt contributed greatly to increasing the instructor pool in the community, leading to growth in the number of training centres and trained providers. This could have indirectly helped to raise the bystander CPR rate in the country.

In order to keep the increasingly large pool of instructors regularly updated on new findings, innovative methods and aspects of resuscitation, the NRC has been organising annual instructor updates since 2008, each of which is usually attended by $400-500$ instructors. Instructors have also used these updates to seek clarification on many aspects of life support training. These sessions, together with the annual National Life Saving Day, have provided ample opportunities for instructors to interact with each other at regular intervals. They are a fairly cohesive unit, and that has made it easier to mobilise them for new community-based programmes over the years.

\section{THE FUTURE OF THE NRC}

In January 2009, a joint meeting was held between the NRC and NFAC to explore joint working opportunities. Out of this grew a proposal to combine the two entities into a single Singapore Resuscitation and First Aid Council (SRFAC). The SRFAC has the following goals: (a) support the teaching and practice of resuscitation of the ill and injured; (b) act as the regulating and coordinating body for the various groups involved in the teaching and practice of the variety of resuscitation skills in the country; (c) promote unity and standardisation in resuscitation practices within the country; and (d) provide direction, national policies and guidelines for the teaching and practice of resuscitation in Singapore.

The proposal was sent to the $\mathrm{MOH}$. After seven years of discussions with the ministry, a pro tem committee has been set up to guide the formation of the SRFAC. The SRFAC will assume the combined duties of the NRC and NFAC in 2018. It will have the unenviable target of eventually having at least one trained first-aider in every household in the country, ${ }^{(17)}$ which is not unachievable. The foundations for achieving this target are now in place with the systems that the NRC has developed over the last 19 years. The new council will look forward to receiving the same level of active support from the public and private healthcare organisations, as well as the numerous accredited training centres and trained instructors.

\section{REFERENCES}

1. Choo $\mathrm{MH}$, Tan $\mathrm{WC}$, Oon $\mathrm{CH}$, et al. Cardiopulmonary resuscitation at the Singapore General Hospital. Ann Acad Med Singapore 1984; 13:542-7.

2. Emmanuel SC. Trends in coronary heart disease mortality in Singapore. Singapore Med J 1989; 30:17-23.

3. Singapore Myocardial Infarction Registry, National Registry of Diseases Office, Ministry of Health, Singapore. Singapore Myocardial Infarction Registry Report No. 2. Trends in acute myocardial infarction in Singapore 2007-2012. Available at: https://www.nrdo.gov.sg/docs/librariesprovider3/Publications---AMI/ sinmyocardinfreg2007-2012.pdf?sfvrsn=0. Accessed January 23, 2017.

4. Ong EH, Chan $\mathrm{YH}$, Anantharaman $\mathrm{V}$, et al. Cardiac arrest and resuscitation epidemiology in Singapore (CARE I study). Prehosp Emerg Care 2003; 7:427-33.

5. Anantharaman V, Chee YC, Koo CC, et al. Cardiac life support training: the Ministry of Health's experience. Ann Acad Med Singapore 1992; 21:51-6.

6. Teo WS. Advanced cardiac life support (ACLS). Singapore Med J 2001; Suppl 1:10-20.

7. Anantharaman V. Automated external defibrillation (AED). Singapore Med J 2001; Suppl 1:4-9.

8. Lim SH. Basic cardiac life support (BCLS). Singapore Med J 2001; Suppl 1:2-3.

9. Teo WS, Anantharaman V, Lim SH. Update on resuscitation 2006. Singapore Med J 2007; 48:100-5.

10. Lim SH. Basic Cardiac Life Support: 2011 Singapore guidelines. Singapore Med J 2011; 52:538-43.

11. Lee F. Defibrillation. Singapore Med J 2011; 52:544-7.

12. Anantharaman V, Gunasegaran K. Advanced Cardiac Life Support guidelines 2011. Singapore Med J 2011; 52:548-56.

13. Singapore National Resuscitation Council's Neonatal and Paediatric Resuscitation Workgroup, Chong NK. Newborn and paediatric resuscitation 2011 guidelines. Singapore Med J 2011; 52:560-72.

14. Anantharaman V; members of the National Resuscitation Council, Singapore. Advisory Statement on: Compression-Only CardioPulmonary Resuscitation. Available at: https://media.wix.com/ugd/ f38905_64d0cd4aa0994bcfa82e997d1 7bbfcbd.pdf. Accessed March 24, 2017.

15. National Resuscitation Council, Singapore. A facility CPR+AED management program. Available at: https://media.wix.com/ugd/f38905_ f66d59095d4a413789cc4a8b9e006e32.pdf. Accessed March 24, 2017.

16. Life Saving Training Centre, Singapore. Available at: http://www.Istc.com.sg/ about-us/. Accessed March 11, 2017.

17. Anantharaman V. Developing resuscitation programmes in the community: the tasks ahead for the National Resuscitation Council. Singapore Med J 2011; 52:634-41.

18. Anantharaman V. Implementation of National Resuscitation Guidelines 2006. Singapore Med J 2011; 52:533-7.

19. Ng YY, Leong SH, Ong ME. The role of dispatch in resuscitation. Singapore Med J 2017; 58:449-52 